The International Journal of Indian Psychology

ISSN 2348-5396 (e) | ISSN: 2349-3429 (p)

Volume 5, Issue 1, DIP: 18.01.041/20170501

DOI: $10.25215 / 0501.041$

http://www.ijip.in | October-December, 2017

Research Article

\title{
Executive Function Intervention in Autism: A Case Study
}

\section{Approach}

\author{
Srabasti Dey ${ }^{1 *}$, Dr. Mallika Banerjee ${ }^{2}$
}

\section{ABSTRACT}

Executive Functioning is a repertoire of a number of complex brain (frontal lobe) abilities that helps to perform goal-directed daily activities with ease. In most of the time this function remains discretely unnoticed because it becomes so typical with human daily activities like planning, working memory functions, set shifting, sequencing etc. unless there is a difficulty in performing such task requiring executive skills. Research has demonstrated that deficits in executive functions are a robust correlate of autism. The present study aims to bring out the efficacy of executive skills, ways of intervening such skills in autism and to figure out the effect of such intervention in their daily life activities. Case study approach has been selected as the methodology. Two cases have been selected and the sessions were conducted on individual basis. Apart from this, case history and observation in both home setting and in formal session has been considered to analyse the data. Sessions were conducted in one to one interaction to determine intellectual impairment of the cases by performance box of Colored Progressive Matrices and to determine baseline measure of executive functioning, Tower of London is used. Intervening sessions were conducted by using several equipment and other daily tasks requiring such skills are enquired and observed. Also post intervening sessions were conducted to see the transfer of training. The result showed progress in carrying out activities requiring executive skills involving planning, mental set shifting and working memory and transfer of training is remarkable in mental set shifting task. The present study left a further chance of investigating the scope of trainability of executive functioning in autism considering large number of participants.

\section{Keywords: Executive Function, Autism, Intervention, Set shifting, Planning}

"Being able to focus, hold, and work with information in mind, filters distractions, and switch gears is like having an air traffic control system at a busy airport to manage the arrivals and departures of dozens of planes on multiple runways. In the brain, this air traffic control mechanism is called executive function” (Shonkoff J.P et.al 2011).

\footnotetext{
${ }^{1}$ Research fellow, Dept. of Psychology, University of Calcutta, West Bengal, India

${ }^{2}$ Ex- Professor, Department of Psychology, University of Calcutta, Kolkata, West Bengal, India *Responding Author

Received: October 03, 2017; Revision Received: October 28, 2017; Accepted: November 23, 2017

(C) 2017 Dey S, \& Banerjee M; licensee IJIP. This is an Open Access Research distributed under the terms of the Creative Commons Attribution License (www.creativecommons.org/licenses/by/2.0), which permits unrestricted use, distribution, and reproduction in any Medium, provided the original work is properly cited.
} 


\section{Executive Function Intervention in Autism: A Case Study Approach}

Executive function (EF) is that complex capacity that calls for a rhythmic amalgamation of several abilities for any task completion, activating functionally the prefrontal cortex. The executive skills that enable to make plans, shift, stay focused, inhibit impulses and recall immediately are not present from birth .These are the potentials that are predisposed and whether to develop these capacities or not depends on experiences during early years of life in childhood, and into adolescence (Shonkoff J.P et.al2011). EF skills grows over time, starting its journey as early as the first year of life which are prominent and further it matures by the developmental years, gradually with experiences, travelling through childhood and into adolescents. (Best \& Miller 2010 Diamond 1991a, 1991b, 2002, 2006) The experience or the condition when it is Autism or other neurodevelopmental disorders executive function deficits have been said to be associated with it. (Russell and Fernandez Dol, 1997). The impairment in EF development in children associated with autism is evident in many studies which explain they are eitherless able to synchronize their capacities of executive skills or it becomes a prominent deficit. (Pennington and Ozonoff, 1996; Pennington et al., 1997)

Three most important dimensions or components of executive functioning that are highlighted in recent studies are working memory, inhibitory control and cognitive flexibility.( Diamond, A., \& Taylor, C.1996, Greenberg, M.T., Riggs, N. R. \& Blair, C. 2007, Rothbart, M.K., Posner, M.I., \& Kieras, J. 2006). Cognitive flexibility is the capacity to promptly switch gears and adjust to changed demands, priorities, or perspectives in the environment. Impairment in such set shifting ability is a prominent feature of executive dysfunction; where the shifting ability is demanded on changing goals or tasks and environment. (Avilia et.al,2003) .Working memory helps in such maintenance of task relevant information and guides the process of task completion. (Logan, 2004; Oberauer, 2010) Working memory is the capacity to hold and manipulate information over short periods of time. Further research has shown that individuals having high capacity of working memory tends to be more strategic (Mendonca,2002;Mc Namara \& Scott, 2001; Weissheimer \& Fortkamp,2004) which relates to strategic behaviour during planning. Planning is a complex goal directed activity, where several alternative moves or actions are required to be executed either by trial and error or by sequential strategies. Thus, working memory, cognitive flexibility and planning are not entirely distinct, rather, they work together to produce competent executive functioning.

In general, cognitive and social capacities in early developmental years are constructed upon the building blocks of EF skills. Executive functioning is considered to be a common denominator for developmental outcomes both in social competence and the adaptive behavior of children with autism. (Elizabeth Pellicano 2012). The rigidity and the variation in autistic a typicality could also be explained by impairment in executive control(Hughes and Russell 1993, Ozonoff, Pennington and Rogers 1991). More specifically the prevalence of autistic symptom i.e. perseveration and the troublesome in cognitive flexibility between responses sets itself explains the most important construct of executive functioning. Difficulties in adapting responses according to changing environmental demand are experience faced by an individual with autism and it can be explained by impairment in 


\section{Executive Function Intervention in Autism: A Case Study Approach}

cognitive flexibility. As earlier as in 1978, Damasio \& Maurer study reveals that deficiency in executive control is a cause of the rigid and repetitive behaviour patterns that characterizing autism.

In daily life activities, executive functions underlie a large number of life skills and behaviours. Starting from as simple abilities as, following one step instruction, following rules, remembering simple rules, seeking alternative method to retrieve a object, till as complex abilities as, following multiple instructions, abiding to situational appropriate rules, remembering strategies and ability to construct a plan, is the range of executive functions. Children uses executive function skills to complete tasks that involve following two or more rules showing that they can alter their attention to make deliberate choices (cognitive flexibility), hold rules mentally as they figure things out (working memory) the strategy to complete the task (planning).

The interrelated executive function skill examples by Best \& Miller (2010); Diamond (1991a, 1991b, 2002, 2006) and developmental tasks requiring executive skills listed by Dawson, Peg and Richard Guare (2010) shows how children develops and experiences executive function skills in the progressive developmental years. They develops ability: to remember that unseen objects are still there, to seek alternate methods to retrieve objects beyond directly reaching for what's in view, to execute simple means-to-ends tasks and twostep plans, to seek alternate methods to retrieve objects, to hold in mind two rules and act on the basis of the rules, to shift actions according to changing rules, to run simple errands, to tidy a room,to perform self-help tasks with reminders, to inhibit behaviours.

The complexity of such cognitive and executive task increases as the developmental years progress. Autism which is a pervasive neurodevelopmental disorder is whether compromised with the executive functions or not and how far the deficit can be assessed and trainable is still a quest to know.

\section{Aim of the study}

The present study is a humble attempt to explore whether executive functioning can be assessed, intervened and improved in the individuals with autism.

\section{METHOD}

\section{Objectives}

The chief objectives of the present study are to:

1) Assess the deficiency in executive skill (planning ability) of the individuals with autism

2) Intervene the executive skills (like set shifting and working memory) of the individuals with autism and

3) To see effect or transfer of training (if any) in planning ability of the individuals with autism. 


\section{Executive Function Intervention in Autism: A Case Study Approach}

Keeping the aim of the study in focus, observations of daily life activities (concerning executive skills), behavioural observations and parental reports are considered which is case specific, in explaining the executive functioning process.

\section{Participants}

The present research work is mainly based on case study approach. Necessary parental permission has been taken and the study is conducted both in the child's home set up (informal) and in a clinic set up (formal). Two cases have been selected on the basis of autism assessment (review of clinical reports and psychometric assessment), intelligence level, observation and case history. Both the cases are within the age range of 7 to 8 years, nonverbal, receiving interventions in special schools for at least one year.

\section{Case 1: Female, 7 years diagnosed Autism}

The first case of the study is a 7years old female child diagnosed with autism. She is receiving special education at a reputed school in Kolkata, West Bengal, India occupational therapy and attending swimming classes where she can float in water with assistance. Case history reveals that she was found to have observable decline in speech and communication after 2 years 6 months before which her developmental milestones were healthy.

Her primary deficits are in communication and socialization and short attention span and repetitive behaviour with perseveratory tendencies. Speech is absolutely declined and she communicates very limitedly using certain signs taught to her like when urinary pressure felt, for food and chocolates etc. She does not respond to her name and does not make eye contact. She does not connect herself with people around. Her strength included developing self-help skills with assistance and motor skills.

\section{Case 2: Male, 7 years diagnosed Autism}

The second case is a 5 years old male child diagnosed with autism. He receives special education at home mainly, occupational therapy, swimming coaches (loves to play in water) and receives training in 'tabla' (type of a drum beaten by fingers) where he enjoys beating the palms. Case history reveals that first speech developed in monosyllabic words at age of 9 to 10 months followed by sudden decline in speech. Now, he uses phonetic sounds (similar to those of spoken words)when asked to communicate and understands and responds to some spoken words like 'good sitting'(seats properly),'hands lock'(stops fidgeting hands), 'thank you', 'Namaste' etc. He makes partial eye contact, follows basic instruction, adopts to reinforces (edible and very rarely social reinforcement).He is prompt and steady in cognitive task(like moving the laptop cursor to open the you tube, matching puzzles building blocks etc) Deficits areas included short attention span, socialization, repetitive behaviour, low motivation in work(when not reinforced), and problem behaviour like spitting.

\section{Tools and its development}

1) Performance box of Colored Progressive Matrices is used in the present study to assess the intelligence level of the participants. The norm for mentally challenged 


\section{Executive Function Intervention in Autism: A Case Study Approach}

group is referred. Colored Progressive Matrices is a form of matrices available for younger children and special groups, who cannot be adequately tested with Standard Progressive Matrices (Raven J. C. 1936) for different ability. It consists of three sets each set containing twelve problems. Presenting the test in colored cards and movable small pieces to fit in the pattern makes the problem to be solved obvious, with the least possible verbal explanation

2) Tower of London (TOL: DX $2^{\text {nd }}$ edition) developed by Culbertson \& Zillmer, 1998 is used to assess planning ability as a measure of executive functioning. Participants were presented with a prearranged sequence of three different colored beads on three different sized pegs. They were required to move the beads to match a test problem determined by the examiner and shown on a parallel board of pegs, in as few moves as possible and in accordance with pre-specified rules.

3) Maze models similar to that of Porteus maze developed by Porteus (1950) were used for training mental set shifting tasks.

4) Blocks and objects were used to impart training for improvement of working memory capacity.

\section{Procedure}

The study has been conducted partially in home set up which is informal environment and also in a clinic set up where the environment is more formal. Home environment is selected to observe the child in his natural setting where he has familiar objects, belongings to use, known space to explore cognitively and family members to interact. The parents and other members in the family related to the child is also sensitized and educated about the happenings of the research work so that they can develop insight to the child's developmental tasks requiring executive skills. Their reports and observations are also considered. Formal setting was in a room of a clinic where mostly the assessment is done .Apart from the observation and reporting, the entire study is launched in three phases mainly pre-training, training and post training sessions.

Pre training sessions were conducted to measure intellectual ability of the participants by performance box of Colour Progressive Matrices and match the subjects by IQ, gender and age in the formal setting. The measure of tower of London (TOL) is taken to assess the baseline ability of executive functioning.

The training sessions (up to 10 sessions) were conducted each ranging 30 to 35 minutes (approx.) and mostly in home environment. Each task is preceded by practice trials to ensure participants comprehension of task instruction.

In block span the examiner pointed to four blocks and the subjects have to point to the block in the same sequence the examiner did. It required the participants to update rehearse and maintain information in working memory to carry out response. In object span, object presentation started with the presentation of three objects and gradually the numbers were increased by one on each succeeding trial. After completion of one category another category 


\section{Executive Function Intervention in Autism: A Case Study Approach}

was introduced. The participants repeated the same presentation recalling the arrangement of the objects in each trial. The next trial is moved only after successful completion of the tasks of recalling and presenting the objects.

In mental set shifting tasks, the participants at first were allowed to reach the goal by using any one alley and in the next trial the learned alley is blocked and they have to shift from the learned alley and reach the goal following the alternative unlearned alley. In this way the participant were made to break the previous set of the last trial. Tasks complexity gradually increased with the difficulty in the successive mazes.

Post training is conducted where measure of TOL was taken in to assess the planning ability after training and to evaluate the transfer of training if any.

Throughout the period of intervening sessions other simple developmental tasks requiring executive skills in home setting were also encouraged to perform. The parents reported about the task and also the researcher's behavioural observation was taken into consideration. This was case specific according to the effort given by the participants and their motivation for the tasks. The executive tasks that were asked to perform are similar to those of developmental tasks listed by Dawson, Peg and Richard Guare (2010) and Best \& Miller (2010); Diamond (1991a, 1991b, 2002, 2006). They are: tidying the floor scattered with bits of papers, taking away finished plates from the table,learning to put two actions together in a sequence( moving the cloth and grasping the toy, filling the container with biscuits and tightening the lid). Though these tasks are not considered as evaluating measures but it leaves a scope to complement the integrated training of executive skills.

\section{RESULT AND DISCUSSION}

Besides, the structured pre training, training and post training sessions, other observations on activities of executive function complements the qualitative indices of the improvement attained by the participants. The finding that contributes in executive function improvement is discussed case wise here.

\section{Case study 1}

Rapport was very hard to establish because she was not connecting herself in the situation. She was mostly engaged in repetitive behaviour like moving tirelessly to and fro in the same place. By suggestion and repetitive instruction she started showing interest in activities but frequently was becoming inattentive. Warm up sessions helped her to engage in the flow of tasks.

In assessing IQ, in pre-training sessions her IQ found to be 80 (Extrapolated Norms for subnormal group of Colored Progressive Matrices).Initially she was not attending the matrices task. First five items in set A were demonstrated to make her understand the pattern of the matrices. From time to time attention needed to be aroused. She was able to perform the tasks only when she was attending to it. The norm suggests maximum up to 11 correct 


\section{Executive Function Intervention in Autism: A Case Study Approach}

items for the age of 7 years accounting to IQ 80. She has attended 15 items correctly and independently without any prompt. This might suggest she is capable of solving matrices more adequately than her age group. Also inattention hindered the performance. Thus, it might be stated that intelligence level could have been more better than the present score.

In assessing Tower tasks she was showing interest and grabbing the beads repeatedly to place it in the peg. The practice problems were demonstrated and the rule (Type I and Type II) of the test were guided throughout the test. She understood the rules and was taking less initiation time (only 12 second in problem no.1)to attend the problem. Initiation time or Planning time, also known as initial think time (e.g., Asato et al., 2006), represents the time from when the participant is first exposed to the TOL problem to the time when the participant picks up the first bead. Performers having high ability in problem solving tasks spent twice as much time on preplanning time(initiation time) as compared to slow performers.( Unterrainer et al. 2004). In the beginning she was solving the problems by trial and error but as the items proceeded she was taking much time to initiate (e.g 45 seconds in problem no. 7) though inattention still persisted. She was attending the problems more once she had already initiated the task and exhibited few planned moves. In pre-training session problem solving time accounted to 899 secs and after a thorough training it accounted to 709 secs, which suggest improvement in planning ability .Different studies have established normative baseline data and measured the extent to which TOL problem solving performance differs in different populations; like some researchers use the number of excess moves to measure performance while others use a perfect solution score while some others used the total cognition time. (SANZEN Neuropsychological Assessment Tests; manual of Tower of London,2012). Here total problem solving time is considered as the basic parameter to compare pre and post condition. The type I and Type II error is also decreased from pre to post condition ( 6 to 2 in Type I; 7 to 5 in type II) suggesting that she can adhere by the rules of the study better in post condition.

In set shifting tasks her performance is mostly significant because as the training period preceded her shifting ability gradually build-up. In initial sessions she was facing maximum up-to 18 obstacles in maze 1 (cannot shift to the unlearned alley, hitting repeatedly the blocked alley which she has learnt to reach the goal). After,10 to 12 trials she was trained to shift the from the learned alley to unlearned alley. As the maze task proceed along with increased difficulty most surprisingly number of obstacles decreased to 8 in the $5^{\text {th }}$ maze. Thus, she was able to shift her mental set smoothly facing fewer obstacles in the learned alley as the training was progressing. The effect of training in shifting tasks was also found in the performance of tower tasks in post condition where the number of her total move score decreased from 33 to 28. (Preto post condition). A lifespan study found an inverse relationship between performance on a shifting task and problem solving ability (Bugg et al., 2006). In other words, better performance on the shifting task was related to fewer excess moves on the TOL task (which demonstrates better performance). Her mother reported that she can use alternate method to perform a task. She usually was unable to reach the rope to hang her wet towel where she saw her mother hanging it. Very surprisingly she hanged the 


\section{Executive Function Intervention in Autism: A Case Study Approach}

towel messily on the little space on a ring beside the wash basin; the tasks that she never did before.

In the activities of working memory, her performance in object and block span is comparatively slow than other tasks. These is because her less attention span. In block span she was not attending to the sequence in which the 4 blocks are touched. In very few trials she was able to correctly maintain the sequence in which the blocks are touched. In contrast, she performed well in the TOL where the TOL itself can be explained as a visuospatial task (Gilhooly et al., 2002) that most likely requires the constant update of working memory in order to keep track of the necessary components of the plan while releasing information that is no longer pertinent. Thus, the reason for slow performance in block span task is unexplained. On the contrary she is quiet able to remember two actions together when enquired in daily life skill tasks. For example unwrapping the chocolate and throwing away the wrap in the bin, keeping the book in the bookshelf and the toy in the toy table.

As reported, she showed significant improvement in developmental tasks like helping mother in household with simple activities like sorting vegetables in separate pouches, putting caps on the filled bottles, making the bed by arranging the pillows in their respective places, arranging plates in the table. Though the tasks were done messily but the initiation in such activities requiring executive skills are attributable to the formal intervention of executive skill or not are still unexplained and needs a detailed probing.

\section{Case study 2}

His psychometric assessment reports (while taking case history) recommended sensory integration therapy as immediate intervention. He feels overwhelming in ordinary situations and faces difficulties in processing sensory information such as textures, brightness and movement. This a common trait found in autism. So warm up exercises was done before getting started with pre training session with a huge ball on which he can roll on. He jumped and played with numerous soft balls and rolled on the soft mattress. This made easier to establish rapport since he enjoyed the play.

His IQ is found to be 80 (Extrapolated Norms for subnormal group of Colored Progressive Matrices). The norm suggest maximum up to 8 correct items for the age of 6 years accounting to IQ 80 . He has attended 20 items correctly and independently without prompt suggesting a high level of intelligence.

Initially there was very low motivation in work. For which correct responses were reinforced intermittently by providing chocolates. His mother reported that he is motivated to work by giving edible reinforcement and thus he is less adapted to social reinforces. He was fidgety but throughout the sessions he responded to verbal instructions like "good sitting", "hands lock" and sat without restlessness. He has the habit of sitting in cut chairs and executes any tasks. 


\section{Executive Function Intervention in Autism: A Case Study Approach}

He is able to follow one step instruction, can delay a treat, and stops himself from touching something when instructed not to do so. His self-help skills are developing with verbal prompt and physical assistance. So, the case history and behavioural observation revealed that the interrelated executive skills (Best \& Miller 2010;Diamond 1991a, 1991b, 2002, 2006) are somewhat present.

In assessing Tower tasks he was unable to complete all the 10 test problems. He successfully completed first 5 problems with prompt. He took total move score 21 and 20 in pre and post condition respectively. The problem solving time decreased from 652 secs to 600 secs and in pre to post condition. The tower task seemed to be difficult task for him as per his planning ability. He was finding it difficult to comprehend about the task and its rules. The literature on the TOL problem solving performance of children demonstrates some consistency in developmental patterns. In general, young children have poor problem-solving performance, but they develop the ability with progressive developmental years (Luciana et al., 2009). Luciana and Nelson (1998) suggest that young children have yet to develop their planning ability and using effectively working memory. Other researchers have proposed that children sometimes face difficulty to search ahead (Kaller et al., 2008). Thus the findings of TOL is shows little significance in pre and post condition. Behavioural observation suggests that he can execute means to ends tasks like building the ring from smaller to bigger in pegs. He was prompt in closing the pop ups by moving the laptop cursor while watching video in you-tube. He has learnt it from his mother. Little direction is needed when performing any simple task independently like fetching the shoe from the shoe self to reach grandmother for her assistance to wear it.

In set shifting tasks he was facing maximum up to 16 obstacles in maze 1.After,10 to 12 trials he was trained to shift the from the learned alley to unlearned alley. As the maze task proceed along with increased difficulty number of obstacles decreased to 2 in the 5th maze. Thus, he was able to shift her mental set smoothly. The chocolates kept in the goal point acted as rein forcers for him in the situation and he performed well in the tasks. His mother reported that he can shift actions to changing demands like seeking assistance to take off the shoe before entering room, reaching for home dress upon reaching home. Training can be satisfactorily provided in the training sessions.

In the activities related to working memory, his performance in object and block span is satisfactory. He can successfully touch the 4 blocks in correct sequence for 5 consecutive trials and in object span he can remember up to 5 objects and arrange it in same order. He enjoyed this training sessions particularly with the models of vegetables and fruits.

He can hold two actions in mind like putting the red beads in the box and blue beads in the bowl. Also he remembers where his belongings are kept and mother's belongings are kept. He picks up the belongings and places the different things in their respective places. 


\section{Executive Function Intervention in Autism: A Case Study Approach}

In a nutshell the executive function skills are not absolutely impaired in both the cases and qualitative analysis shows that training can be provided in set shifting tasks. The positive effect or transfer of training in set shifting task is found on planning ability (performance of TOL task) of the first case in. Working memory deficits have been found in autism (Bennetto et al., 1996), but not consistently (Ozonoff \& Strayer, 2001; Russell, Jarrold, \& Henry, 1996).This is true for the second case in the present study where he performed satisfactorily in activities related working memory. The findings in the present study need more replications to be able to generalize the outcome of the study. Standardized inventories can be a check to the life skill tasks relating to executive function skills.

\section{Acknowledgments}

The author appreciates all those who participated in the study and helped to facilitate the research process.

Conflict of Interests: The author declared no conflict of interests.

\section{REFERENCES}

Bamberg, M. (2010b). Who am I?--Narration and its contribution for self and identity. Theory \& Psychology, in press.

Cain, Carole (1991) Ethos, Vol 19(2), Jun 1991, 210-253.

Calvin Morrill, Christine A. Yalda, Madelaine Adelman, Michael Musheno, and Cindy Bejarano. "Telling Tales in School: Youth Conflict and Culture Narratives" Law and Society Review 34.3 (2000). Personal stories: Identity acquisition and selfunderstanding in Alcoholics Anonymous.

Chase, S. (2005). Narrative inquiry: Multiple lenses, approaches, voices. In Denzin, N.K. \& Lincoln, Y.S. (Eds.), The SAGE handbook of qualitative research (3rd ed.), pp. 651679. Thousand Oaks, London, \& New Delhi: Sage Publications.

Clandinin, D. J., \& Connelly, F. M. (2000). Narrative inquiry: Experience and story in qualitative research. San Francisco: Jossey-Bass.

Czarniawska, B. (2004). Narratives in Social Science Research. Introducing Qualitative Methods. London: Sage Publications.

Daiute, C. \& Lightfoot, C. (Eds.). (2004). Narrative Analysis. Studying the Development of Individuals in Society. Thousand Oaks, Sage Publications.

Denzin, N. K. (1989a). Interpretive biography. Newbury Park, CA: Sage.

Gee, J.P. (1991) “A linguistic approach to narrative”, Journal of Narrative and Life History, 1: $15-39$.

Hiles, D.R., \& Cermák, I. (2008). Narrative psychology. In C. Willig \& W. Stainton-Rogers (Eds.), Sage handbook of qualitative research in psychology (pp. 147-164). London: Sage.

Hinchman, L.P. and Hinchman, S.K. (eds) (1997) Memory, Identity, Community: The Idea of Narrative in the Human Sciences, Albany NY, State University of NY Press. 


\section{Executive Function Intervention in Autism: A Case Study Approach}

Hollway, W., \& Jefferson, T. (2008). The free association narrative interview method. In L. Given (Ed.), The SAGE encyclopedia of qualitative research methods (pp. 286-315). Thousand Oaks, CA: Sage.

Labov, W. (1972). Language in the inner city. Philadelphia: The University of Pennsylvania Press.

Labov, W. (1982) "Speech actions and reactions in personal narrative”, in D.

Mandler, J., \& Johnson, N. (1977). Remembrance of things parsed: Story structure and recall. Cognitive Psychology, 9, 111-151.

Mishler, E.G. (1995) "Models of narrative analysis: A typology", Journal of Narrative and Life History, 5(2): 87-123.

Pinnegar, S., \& Daynes, J. G. (2006). Locating narrative inquiry historically: Thematics in the turn to narrative. In D. J. Clandinin (Ed.) Handbook of narrative inquiry: Mapping a methodology (pp.3-34). Thousand Oaks, CA: Sage Publications, Inc.

Plummer, K. (1983). Documents of life: An introduction to the problems and literature of a humanistic method. London: George Allen \& Unwin.

Polkinghorne, D.E. (1988). Narrative knowing and the human sciences. Albany. NY. State University of New York Press

Riessman, Catherine Kohler (2005) Narrative Analysis. In: Narrative, Memory \& Everyday Life. University of Huddersfield, Huddersfield, pp. 1-7.

Shonkoff J.P et.al 2011 Center on the Developing Child at Harvard University (2011). Building the Brain's “Air Traffic Control” System: How Early Experiences Shape the Development of Executive Function: Working Paper No.11. http://www.developing child.harvard.edu

Tannen (ed) Analyzing Discourse: Text and Talk, Washington DC, Georgetown University Press.

Thorndyke, P.W. (1977). Cognitive structures in comprehension and memory of narrative disourse. Cognitive Psychology. 9, 77-110.

Wengraf, T. (2006). Interviewing for life-histories, lived situations and personal experience. The biographic-narrative interpretive method (BNIM) on its own and as part of a multi-method full spectrum psychosocial methodology.

How to cite this article: Dey S, \& Banerjee M (2017). Executive Function Intervention in Autism: A Case Study Approach. International Journal of Indian Psychology, Vol. 5, (1), DIP: 18.01.041/20170501, DOI: 10.25215/0501.041 